\title{
THE PRICE OF RISK IN THE SOUTH AFRICAN EQUITY MARKET
}

\author{
NICHOLAS LAWRENCE SAMOUILHAN*
}

\begin{abstract}
This paper investigates domestic risk-return behaviour by focussing on the intertemporal relationship between the conditional domestic equity market premium, its conditional variance and its conditional covariance with the international equity market. The paper finds that the domestic equity market prices in both domestic and international diversification risk. The estimated daily price of domestic variance risk is $0.0279 \%$ (EAR: $7.28 \%$ ) for every one unit of expected domestic variance. The estimated daily price of covariance risk is $0.0111 \%$ (EAR: $2.83 \%$ ) for every unit of expected covariance risk. The representative domestic investor values domestic variance more than covariance risk. The variances of domestic and international equity returns are found to be time-varying, as is the covariance between the two. Evidence is found that the Johannesburg Securities Exchange is not perfectly integrated with the world economy, in an absolute sense. The volatility spillover effect is observed to be both significant and positive. The standard Capital Asset Pricing Model misspecifies the return to domestic risk, biasing the risk-return coefficient upwards. Domestic investors are rewarded for holding internationally diversified portfolios, with an internationally diversified portfolio expected to have an additional daily return of $0.0238 \%$ (EAR: $6.29 \%$ ) for the same level of risk as an entirely domestic equity portfolio.

JEL Classifications: F36, G12, G15

Keywords: Equity risk, JSE, ARCH-M
\end{abstract}

\section{INTRODUCTION}

At the heart of the study and practice of financial economics is the fundamental relationship between risk and return; being risk-averse, investors require higher returns to compensate them for accepting higher risk. This is the reason why junk bonds, for example, pay higher rates of return than government bonds, and why start-up firms raise capital at much higher interest rates than blue chip firms do. It is also the reason why equities provide greater returns than other, less risky investment classes, such as cash or bonds over a medium to long-term horizon. In an efficient market accepting risk is rewarded; however, and this is basis for financial research, not all risks are equally rewarded. "Optimal investment behaviour", as Engle (2004) states in his Nobel lecture, "takes risks that are worthwhile", seeking out strategies that maximise expected returns and minimise expected risks.

Within the equity market this avoidance of risk leads naturally to a policy of portfolio diversification. As it is unlikely that any two given equities are perfectly correlated with

* School of Economics, UCT. A version of this paper originally appeared as an ERSA working paper (\#49). The author is indebted to Dr C. P. Van Walbeek and anonymous referees from both ERSA and the journal for many helpful comments made on earlier drafts. Any errors or omissions however remain the authors' responsibility. Funding from ERSA for this paper is gratefully acknowledged.

Correspondence: nsamouilhan@commerce.uct.ac.za 
each other, holding more than one equity asset leads to a reduction in risk as the various movements of the assets' partially offset each other. Taking this strategy to its fullest extent possible, the most diversified exclusively equity portfolio an investor can hold consists of all of the assets held in proportion to their market capitalisation, a portfolio known as the market portfolio. The fully diversified property of the market portfolio ensures that its variance, or risk, plays an important role in defining the "base" level of risk in an equity market. For example, in the well-known Capital Asset Pricing Model (CAPM) of Sharpe (1964) and Litner (1965) the risk premium of the equity market is determined by the market price of risk (related to the risk averseness of the investors) multiplied by the variance of the market portfolio.

However, in a globally open equity market such as South Africa's, it is possible to diversify further than the market portfolio by investing in the international equity market. This allows for further risk reduction, as international equity markets, while tending to move together in general, are imperfectly correlated given their respective local market conditions and differing bourse compositions. The diversification aspect of an international portfolio obviously depends on the degree to which the returns on the respective international bourses move together. From this risk-reducing portfolio perspective, investors seek decreased correlations between the equities markets and avoid increased correlations. From a risk-averse international equity portfolio's perspective, increased correlations are a risk that should be rewarded in an equity market such as South Africa's, in additional to the "base" risk of the market portfolio.

The aim of this paper is to investigate empirically the risk-return relationship on the Johannesburg Securities Exchange (JSE) by focussing on the returns to these two risks. Accounting for the forward looking nature of equity investing, it will do so by focussing on the relationship between the expected return on the market portfolio, its expected variance (domestic risk) and its expected covariance (international diversification risk) with the international equity market, using the London Stock Exchange (LSE) as the global market proxy. Furthermore, the paper will investigate these domestic and international risk prices within a framework that accommodates two important and salient properties of the JSE.

First, the framework allows for international spillover effects between the international equity market and the domestic market. Many studies have documented the association, or co-movement, of domestic and international returns and variances across a wide range of countries. As just one such example, Hamou et al. (1990) find significant evidence of an association between returns and volatilities on the LSE, the New York Stock Exchange (NYSE) and the Tokyo Stock Exchange (TSE), while Samouilhan (2006) documents the same significant link between the JSE and the LSE returns and volatilities. To accommodate this important source of information regarding domestic equity movements this risk-return study will follow Lin et al. (1994) in using a Factor-ARCH volatility specification that accommodates the spillover relationship between foreign and domestic volatilities. This explicit inclusion will allow for the both the estimation of the degree of volatility spillover and better modelling of the domestic volatility process.

Second, the model accommodates the well-documented time variation in both the variances and covariances of the equity returns. Volatility clustering, where volatile periods follow similar volatile periods, and calm periods follow equally calm periods, is an innate property of financial time series. This is because a large shock in a certain direction is often followed by another large shock of a similar magnitude, either in the same 
direction (herding behaviour) or in the opposite direction (mean reversion behaviour or correction) as market participants endeavour to correctly price in the new information. Likewise, small shocks in a certain direction tend to follow small shocks of a similar magnitude, again in either direction. As international equity markets tend to move together this clustering property is also apparent in the covariance between two or more equity markets. To accommodate this salient time variation this paper will employ ARCH processes to model the variances and covariances of the two markets under review.

The paper finds significant evidence that the domestic market prices in both of these risks, and that these returns are quite substantial. The results are in line with studies of other major equity markets, and provide evidence that the two-factor Intertemporal Capital Asset Pricing Model (ICAPM) is preferable to the single-factor CAPM in estimating the domestic risk-return relationship. The paper also finds that movements in the international equity market have two effects on the local market: increasing the risk of the domestic market by reducing the international diversification benefits, and explaining some of the volatility of domestic equities. The gains from having an international diversified portfolio are positive and relatively large for SA investors, suggesting that the small home market allows them to gain more from such a global portfolio than investors in large home markets such as the US.

The structure of this paper is as follows. The next section discusses the price of risk and the ICAPM used in this paper, while section 3 presents the literature review. Section 4 provides the econometric specification of such an ICAPM model, while section 5 provides the results and analysis. Section 6 concludes.

\section{THE INTERTEMPORAL CAPM AND THE PRICE OF RISK}

The basis for this domestic risk-return study is the ICAPM of Merton (1973). This is the multi-period extension of the static CAPM, and holds that investors attempt to maximise utility over the total investment horizon. Whereas the CAPM implies a simple relationship between the market risk premium and the conditional risk premium, the ICAPM is a multifactor asset-pricing model where the risk premium on an equity market is a function of whatever risk source(s) the representative investor decides to price, or impound, into the asset price. Given the characteristics of equity returns, the conditional market variance is usually one of the risk factors. Given the open nature of the JSE, this study investigates the hypothesis that the representative investor on the JSE, in addition to pricing in market variance risk, prices in the risk surrounding the loss of diversification benefits.

\section{(a) Variance and Covariance Risk}

That the expected variance of returns is a major, if not the major, source of risk amongst equities has a long history in financial economics, stretching back to Markowitz (1952) and Tobin (1958), and is the standard risk measure in the equity risk-return literature. As the definition of an equity return is the movement of its market price, the expected variance associated with this expected return is a direct measure of future uncertainty (or risk) surrounding such an investment. In the literature, the expected return per unit of the expected variance of returns is often termed Lambda $(\lambda)$, a convention this paper will follow in describing the risk price. Given the risk-averseness of the representative investor, it is expected a priori that Lambda will be both significant and positive in the South 
African equity market. This is because the risk-return relationship states that in an efficient market the expected return should be higher if the expected uncertainty of that return is higher, provided the market prices in this domestic variance risk.

The second risk factor explored in this paper concerns the uncertainty around international diversification. In the relatively open South African equity market, international investors are able to invest in domestic assets and, conversely, domestic investors are able (to a large degree) to invest in international assets. While obviously seeking higher risk adjusted returns, a significant attraction of this cross border investing must be due to the increase in diversification generated from such cross border portfolios. Given the imperfect correlations amongst international equity markets, investing in offshore equities should reduce some of the risk of investing in domestic equities. From such an international portfolio investor's perspective the less correlated the domestic market is with the international market the better this diversification property of the JSE, and vice versa. Assuming that risk-averse investors desire this diversification property, the domestic market will price this increased covariance between the domestic and international market into the domestic market as a risk. In an efficient market, therefore, investors valuing international diversification should receive a higher expected return in compensation for the higher expected covariance. A priori, the expected price of this covariance risk should be positive. As there appears to be no universal name for such risk in the literature, this paper will refer to this covariance risk as Kappa $(\kappa)$.

It is important to note that this international risk discussed here and investigated in this paper is covariance risk, and not contagion risk. While clearly related, these two risks have very different effects on the risk-return relationship. Covariance risk is due to the decrease in the diversification benefit as domestic and international returns move more closely together. Contagion risk, on the other hand, is the risk that international equity price movements will affect domestic price movements. This is due to the tendency of investors to price in information from outside the borders of their respective country into their own equity market, leading to price movements internationally "spilling over" into the domestic equity market. While clearly a risk, contagion risk is priced in indirectly in this paper through its affect of the domestic volatility level. As such, there is no "contagion price" estimated in this paper. The price of covariance risk in contrast is investigated in this paper; being captured in the conditional covariance term in the conditional first moment specifications of the respective returns. (See below for the exact specification of these effects and further discussion.)

There are thus two distinct though related international effects investigated and accommodated in this study. The paper accommodates the spillover effect, whereby increased volatility on the international market is associated with increased volatility on the domestic market, through the inclusion of the foreign volatility in the specification of the domestic volatility. Covariance risk, where the international and domestic market move more closely with each other and therefore lessen the diversification effect, is accommodated though the inclusion of the estimated conditional covariance in the specification of the domestic return. This modelling of two distinct effects from the same source, with one effect priced in by the market as a risk and the other a contributing factor affecting the volatility, follows the exact procedure used by Dean and Faff (2001) to incorporate bond market risk into their ICAPM model of Australian equity returns. 


\section{(b) The Intertemporal Capital Asset Pricing Model}

With this understanding, as a starting point for the specification used in this paper to price the two risks, define the return premium for asset $\mathrm{i}\left(\mathrm{r}_{\mathrm{i}, \mathrm{t}}\right)$ as the nominal return $\left(R_{i, t}\right)$ less the risk free rate return $\left(R_{i, t}\right)$ for time period $\mathrm{t}$ as:

$r_{i, t}=R_{i, t}-R_{i F, t}$

In the standard CAPM model there is a simple proportional relationship between the market risk premium $\mathrm{r}_{\mathrm{i}, \mathrm{t}}$ and one risk factor, the conditional risk premium:

$$
E\left[r_{i, t} \mid \Omega_{t-1}\right]=\beta_{A} E\left[\operatorname{var}\left(r_{i, t} \mid \Omega_{t-1}\right)\right]
$$

Where $E\left[\cdot \mid \Omega_{\mathrm{t}-1}\right]$ is the expectational operator conditional on information known in the immediately preceding period $\left(\Omega_{\mathrm{t}-1}\right)$.

Then, the two-factor ICAPM extension of the CAPM model has the market risk premium of portfolio $\mathrm{i}$ being proportional to the covariance of the returns with the returns of two risk factors, $\mathrm{A}$ and $\mathrm{B}$ :

$$
E\left[r_{i, t} \mid \Omega_{t-1}\right]=\beta_{A} E\left[\operatorname{cov}\left(r_{i, t}, r_{A, t} \mid \Omega_{t-1}\right)\right]+\beta_{B} E\left[\operatorname{cov}\left(r_{i, t}, r_{B, t} \mid \Omega_{t-1}\right)\right] 4
$$

The ICAPM specification of the market portfolio used in this paper has the international market being one factor and the domestic market portfolio being the other. Noting that the covariance of the market portfolio with itself is by definition the variance of the market portfolio, the ICAPM specification for an international market portfolio $\mathrm{J}$ is specified as:

$$
E\left[r_{J, t} \mid \Omega_{t-1}\right]=\lambda_{\text {var }} E\left[\operatorname{var}\left(r_{J, t} \mid \Omega_{t-1}\right)\right]+\kappa_{\mathrm{cov}} E\left[\operatorname{cov}\left(r_{J, t}, r_{L, t} \mid \Omega_{t-1}\right)\right]
$$

where the expected return premium on the international equity portfolio is proportional to the expected variance risk of that portfolio and proportional to the expected covariance risk of the portfolio with the international equity market. $r_{J t}$ and $r_{L t}$ are the excess returns on the JSE and the foreign market (LSE) for time period $t, \lambda_{\text {var }}$ is the price of domestic risk Lambda and $\kappa_{\text {cov }}$ is the price of covariance risk Kappa. Equation (4) thus gives the relationship at time $\mathrm{t}$ between the expected market return premium, the expected domestic market risk and the expected international market risk, all conditional on the information known at period t-1. Essentially, this is a specification regarding the forward looking return to risk on the JSE.

\section{(c) A Unit of Risk}

Given the construction of variance measure casual interpretation of the return per unit of risk is conceptually untidy as the power transformation of the variance specification renders easy interpretation and application of the variance units messy. The simplest case is the interpretation of one unit of risk, which, assuming a symmetrical distribution, can be seen as a level of uncertainty corresponding to a full $1.00 \%$ return above or below the expected return. Interpretations of higher variance amounts quickly lose their practical traction. Two units of risk, for example, correspond to a level of return uncertainty of approximately $1.41 \%(\sqrt{2})$ above or below the expected return; three units correspond to $1.73 \%(\sqrt{ } 3)$ above or below. For ease of interpretation, this paper will frame all discussion 
of the returns to risk in terms of returns per single unit of risk, equivalent to a level of uncertainty of a full 1-percentage return around the expected return.

\section{(d) Market Segmentation and Benefits from International Diversification}

An interesting aspect to this dual study of domestic and international risk, as outlined by De Santis and Gerard (1997), is that it is possible to infer some information about the integration of the domestic market with the international market, at least in an absolute manner of integration, from the relative returns to these two risks. A market perfectly integrated with the international equity market (in the extreme sense of word), would have all of the significant information regarding the risk return relationship contained in the international market risk term, and the information regarding domestic risk would not matter. Evidence then of a significant country specific risk in the estimation of the equity returns which also contains the international risk information could be seen as suggesting that the local market is not perfectly integrated with the world equity market. There would be at least some market segmentation on the national level as domestic risk information is still significant in explaining the equity returns. While not a principle focus of this study, the econometric framework employed will allow this segmentation hypothesis to be tested: if the domestic market was perfectly integrated internationally only international information would matter, making Lambda in equation (4) insignificant. As such, following De Santis and Gerard (1997), equation (4) is also a test of market integration, if only at a very broad level.

De Santis and Gerard (1997) also show that the estimation of the returns to such an international portfolio can be used to gauge the gains from international diversification. Consider a domestic equity investor with no international investments, i.e. a portfolio composed entirely of domestic assets. According to equation (4), including foreign equities in this portfolio will expose the representative investor to diversification risk, which will provide an expected payoff of $\left(\kappa_{\mathrm{cov}} E\left[\operatorname{cov}\left(\mathrm{r}_{\mathrm{j}, \mathrm{t}}, \mathrm{r}_{\mathrm{L}, \mathrm{t}} \mid \Omega_{\mathrm{t}-1}\right]\right)\right.$. It is clear that, by definition, the domestic portfolio has a volatility level of the domestic market portfolio, $\left(E\left[\operatorname{var}\left(\mathrm{r}_{\mathrm{j}, \mathrm{t}} \mid \Omega_{\mathrm{t}-1}\right]\right)\right.$. It should also be clear that, for the same level of volatility, an internationally diversified portfolio has an increase in returns equal to $\left(\kappa_{\mathrm{cov}} E\left[\operatorname{var}\left(\mathrm{r}_{\mathrm{j}, \mathrm{t}} \mid \Omega_{\mathrm{t}-1}\right]\right)\right.$. Therefore, following De Santis and Gerard for a level of risk equal to the domestic level the expected gain to a portfolio with international diversification over a portfolio with zero international diversification portfolio is given by:

$$
E\left[r_{\text {diversifed }, t}-r_{\text {closed }, t} \mid \Omega_{t-1}\right]=\kappa_{\mathrm{cov}} E\left[\operatorname{var}\left(r_{J, t} \mid \Omega_{t-1}\right)-\operatorname{cov} E\left(r_{J, t}, r_{L, t} \mid \Omega_{t-1}\right)\right]
$$

The estimation of equation (5) will therefore also allow for the indirect investigation of the possible gains to local investors having for an internationally diversified portfolio.

\section{LITERATURE REVIEW}

Given the importance of estimating the compensation for risk, it is not surprising that this has been a very productive research field. However, it is worrying that despite there being a strong theoretical reason for the existence of a positive return to these risks, there is no consensus in the literature regarding the size, significance or even the sign of such a risk price coefficients. 
For example, looking at the major world equity markets, first French et al. (1987), using daily returns on the $S \& \mathrm{P}$ index, find a positive though insignificant price estimate of domestic risk of $0.023 \%$ using a GARCH-M model. Chou et al. (1992) use a Kalman filter and a time-varying ARCH-M model on weekly S\&P composite index returns and find that the price of domestic risk is both significant and positive, though highly time-varying. Using a methodology similar to this paper, De Santis and Gerard (1997) find that the US market prices in both variance and covariance risk. In complete contrast, Glosten et al. (1993) find a significant negative relationship between domestic variance and returns on the US equity market, a finding that is difficult to reconcile with the other empirical studies and conventional asset valuation theory. ${ }^{1}$ This negative result is also found by Campbell (1987) and Pagan and Hong (1991). Chan et al. (1992), meanwhile, employing a bivariate GARCH-in-Mean specification on daily S\&P 500 data, find that the US market impounds in the covariance risk with of the world equity market but does not impound domestic variance ${ }^{2}$ information.

In terms of smaller equity markets, Hansson and Hördahl (1997) apply various ARCH processes specifications to modelling the price of risk on the Swedish equity market, which, in being both small, liquid and relatively open, is similar in many ways to the JSE. Using a standard one factor CAPM their paper generates estimates of Lambda for daily equity index returns ranging from $0.050 \%$ to $0.075 \%$. Dean and Faff $(2001)$, in a very similar methodology to this paper, investigate the return to risk on weekly Australian equity returns according to a two factor ICAPM mode estimated using an EGARCH(1,1)-in-mean model (which allowed for asymmetric variance dynamics) and a dynamic conditional correlation for cross over effects. Focussing on the return to domestic variance risk and covariance risk with regards to the bond market, they find returns to the risks of $0.0876 \%$ to $0.0993 \%$ and $-1.273 \%$ to $-1.786 \%$, respectively. Jochum (1999), using a bivariate $\operatorname{GARCH}(1,1)$-in-Mean methodology, estimates the price of variance and covariance risk of the Swiss Market Index daily returns with regards to the major equity markets of Tokyo, Frankfurt, London and New York. It is not clear how the paper addresses the problem of non-concurrent trading hours. Using a peculiar weighting procedure, whereby the two risks are weighted in proportion to their respective market capitalisation, the paper finds significant evidence that the covariance risk is significant and positive for all the markets except Frankfurt. This daily covariance risk price ranges from $0.089 \%$ for Zurich-Tokyo to $0.396 \%$ for Zurich-London. Surprisingly, though in line with Chan et al., Jochum finds no significant price for domestic risk, though this may be due to the very small importance attached to domestic information given the weighting procedure used in the study.

\footnotetext{
1 There are two possible theoretical reasons whereby such a negative relationship might exist. First, it may be, by coincidence, that investors are able to bear higher levels of risk during the risky periods. Second, if there is no/limited risk free asset(s) and investors wish to save more during a risky period then they will bid up the price of the risky assets (equities) and hence reduce the risk premium and cause a negative relationship to exist. See, among others, Abel (1988) and Glosten and Jagannathan (1987) regarding such theoretical models.

${ }^{2}$ However, they point out that this is probably due to a large degree of multicollinearity between the two risks in their sample, given the dominant contribution, and hence closer relation, of the US equity market to the world equity market.
} 
In South Africa, the risk-return relationship has attracted considerable interest, though these largely focus on the ex post relationships and/or use incomparable non-econometric techniques such as the well-known Sharpe Ratio. To the authors' knowledge, this is the first econometric study of the conditional returns to conditional risks amongst domestic equities using a GARCH-M methodology comparable to the studies reviewed above.

Scruggs (1998) provides a plausible explanation for such widely disparate empirical results in the literature, despite the strong theoretical basis. Investors' price assets according to many different risk factors, and as such the risk return relationship is complex and multifaceted. By using the simple one factor CAPM model, Scruggs argues, many of the studies outlined above ignore important information about the risk structure, to the degree that the bias caused by the omitted variable could significantly distort the results.

Through positing that some significant information that investors price into the market in an open, small equity market such as South Africa's is partly domestic risk and partly international diversification risk, this paper attempts to add to this risk pricing literature as well as counter the problem of insufficient risk specification mentioned by Scruggs (1998). Indeed, this positing of the international diversification effect as another risk factor of key importance to an open equity market such as South Africa's is a key innovation in this paper. In this light, and to test Scruggs's argument that the simple CAPM will provide distorted values of Lambda, this paper will also test the standard $\mathrm{CAPM}$ as an additional risk return model for comparison sake.

\section{METHODOLOGY}

\section{(a) ICAPM Econometric Specification Used}

For this empirical study equation (2) outlined in section 2 is investigated using a parsimonious bivariate GARCH(1,1)-in-Mean specification. Following the ICAPM model the returns on the JSE are modelled as being a function of their own variance and its covariance with the LSE returns. The LSE returns are in turn modelled following a CAPM model, being a function of their own variance only. For both of these the conditional means are regressed upon the conditional variance (and covariances) of the indexes following the ARCH-in-Mean methodology of Engle et al. (1987). The variances of both the LSE and JSE returns are specified according to a $\operatorname{GARCH}(1,1)$ specification. The covariance is modelled according to a $\operatorname{GARCH}(1,1)$ type specification, including an explicit international spillover term.

Specifically, the econometric formulation of equation (2) above is given by: First Moments:

$$
\begin{aligned}
& r_{J, t}=\lambda_{J} h_{J, t}+\kappa_{j} \operatorname{cov}_{J L, t}+\tau_{J} o u t+\varepsilon_{J, t} \\
& r_{L, t}=\lambda_{L} h_{L, t}+\varepsilon_{L, t}
\end{aligned}
$$

with

$$
\begin{aligned}
& \varepsilon_{J, t} \sim\left(0, h_{J, t}\right) \\
& \varepsilon_{L, t} \sim\left(0, h_{L, t}\right)
\end{aligned}
$$


Second Moments:

$$
\begin{aligned}
& h_{J, t}=\omega_{1}+\beta_{1} h_{J, t-1}+\rho_{1} h_{L, t}+\alpha_{1} \varepsilon_{j, t-1}^{2} \\
& h_{L, t}=\omega_{2}+\beta_{2} h_{L, t-1}+\alpha_{2} \varepsilon_{L, t-1}^{2} \\
& \operatorname{cov}_{J L, t}=\omega_{3}+\beta_{3} \operatorname{cov}_{J L, t-1}+\alpha_{3} \varepsilon_{J, t-1} \varepsilon_{L, t-1}
\end{aligned}
$$

The equations for the first moments (equations (6) and (7)) follow directly from the ICAPM model outlined in section 3 above. The excess return is proportional to the domestic variance risk and proportional to the international covariance risk. The realised return at period $\mathrm{t}$ is assumed to be an unbiased estimate of the conditional excess return expected at time $\mathrm{t}-1$. The terms $h_{J, t}, h_{L, t}$ denote the estimated conditional variances of the JSE and LSE equities, respectively, for time period t estimated according to equations (8) and (9). The parameter $\operatorname{cov}_{\mathrm{JL}, \mathrm{t}}$ is the conditional covariance between the equity returns on the JSE and LSE expected for time period t, estimated according to equation (10). The coefficients $\lambda_{\mathrm{J}}, \lambda_{\mathrm{L}}$ and $\kappa_{\mathrm{J}}, \kappa_{\mathrm{L}}$ give the returns to domestic variance and covariance risk on the JSE and LSE, respectively. These are the measures of variance and covariance price central to this study. As is standard in the literature these risk returns are assumed constant over the estimation horizon for reasons of tractability, implying that the slope of the Capital Market Line is constant. The $\tau_{j}$ out term accommodates the outliers (see below) in the domestic equity returns. Finally, the residuals to these mean specifications are assumed to have a mean of zero and a variance of $h_{i t}$.

The variance equations (8) and (9) are standard $\operatorname{GARCH}(1,1)$ specifications of the volatility structure. Among many others, Bollerslev et al. (1992) find that ARCH effects are significant in equity markets, and that the $\operatorname{GARCH}(1,1)$ framework provides a reasonably good and yet parsimonious specification of such time variation. This was borne out in this study, where initial exploratory modelling showed that the $(1,1)$ structure was superior in accommodating the ARCH effects in the domestic and foreign returns than $(1,2),(2,1),(2,2)$ and higher specifications according to the ARCH LM test. ${ }^{3}$ Importantly, after the application of the $\mathrm{GARCH}(1,1)$ model no significant ARCH effects remained in both equity series. The variance equations according to this specification consist of a mean reversion level of volatility $\omega_{\mathrm{i}}$, the $\beta_{i}$ weighted one period lagged conditional variance and the $\alpha_{\mathrm{i}}$, weighted squared residual return from the mean equation. The domestic variance equation was adjusted in a Factor ARCH manner to accommodate international spillover effects present in an open equity market such as South Africa's, with the conditional variance equation for the JSE at time $t$ including the conditional variance of the LSE for the same time period t. Following convention, this is called the spillover term. With this modification, the effect of foreign information on the domestic market can be estimated and its effects accommodated. This spillover modification was not repeated for the variance equation of the LSE for three reasons. First, this study is primary focussed on the JSE and not the LSE, so the quantification of this effect is of no real interest here. Second, the initial OLS estimations show that the

\footnotetext{
3 The ARCH LM tests were conducted at a lag of 20, which corresponds to a full month of trading. Tests at different lags made no difference to the conclusions drawn.
} 
domestic conditional variance term is highly insignificant in explaining the conditional variance on the LSE, in contrast to the highly significant effect the conditional LSE variance has on the JSE variance. It appears that there is a LSE on the JSE effect but no JSE on the LSE effect. This is probably due to the large difference in relative market capitalisation between the two markets. Last, the inclusion of such a term adds unduly to the difficulty in finding convergence in such an already complex model.

It should be pointed out that an asymmetric version of the two conditional volatilities, for example an $\operatorname{EGARCH}(1,1)$ or $\operatorname{TARCH}(1,1)$ model, was not used purely for computational constraints. While it is accepted that the leverage effect, whereby negative returns are followed by increased volatility when compared to a positive return of the same magnitude, is likely to be present, attempts to find convergence in such an asymmetric specification for this paper were not successful. Indeed, given the increased complexity of such a model this is not a unique finding, see Dean and Faff (2001). As the ARCH LM test showed that no significant ARCH effects remained after the application of the symmetric GARCH $(1,1)$ specification it is judged though that the $\operatorname{GARCH}(1,1)$ specification will model the volatility process sufficiently for this study.

The conditional covariance (equation (10)) has a similar time-varying structure to that of the conditional variances. It consists of a mean covariance level $\omega_{3}$ and a one period lagged covariance weighted by $\beta_{3}$. The $\alpha_{3}$ weighted term consists of the interaction between the previous periods' residual returns, in this way it contributes to the covariance equation in the same way that the ARCH term's do in the variance equations. This term provides for the return innovations in the two respective markets to affect the conditional variance between them. The $\alpha_{3}$ term should be positive as contemporaneous negative (or positive) returns on both indices imply an increase in covariance between both markets. In the same way, price movements in opposite directions imply less covariance between the markets. In addition, the lagged covariance term accommodates the potential clustering of the covariance between the two markets. It is conceivable that, like the variances, periods of high levels of covariance are likely to follow periods of similar high covariance, and periods of low covariance followed by similar low covariance.

The model outlined above is thus an econometric specification of the domestic returns with domestic variance risk and covariance risk as the two sources of risk the typical investor is hypothesised to price in. Dealing with salient features of the domestic market it is modelled within a framework that accounts for both international spillover effects and time variance in the individual variances and overall covariance.

A final point is that this paper is concerned with the risk-return behaviour over the entire sample, and the results should be read as such. Given the irregular nature of financial risks and returns, the relationships estimated are likely to display a large degree of time variation over the sample. The investigation of this time conditional aspect of risks and returns, as done by Chou et al. (1992), was not undertaken in this paper for two reasons. First, the use of the reduced sample periods needed for rolling regressions or sub-sample window estimations greatly reduces the likelihood of convergence. This was borne out by initial exploratory tests using only the major annual sub-periods, where it was often impossible for the heuristic to find a solution. Second, this time variation behaviour of the domestic risk-return relationship is importantly not the primary aim of this paper, which focuses on testing for the existence of such a relationship with regards to the returns to risks over the full sample. 


\section{(b) Additional CAPM Econometric Specification Used}

As an additional check on the estimated price coefficients, and to investigate the claim by Scruggs that the simple CAPM model will provide biased estimates of the price of risk if the true model of domestic risk is given by equation (4), this paper will estimate the standard CAPM in addition to the main study of the ICAPM. For domestic equity returns the econometric specification of the one factor CAPM, where the only risk factor investigated and priced is the domestic variance, is given by restricting all foreign variables in the ICAPM model to zero, i.e. imposing coefficients of zero on all the variables denoted by the $\mathrm{L}$ subscripts in equations (6) to (10), including the covariance term. This will modify the equations of section 4.i into a CAPM model estimated according to a standard $\operatorname{GARCH}(1,1)$-in-Mean specification.

Scruggs shows ${ }^{4}$ that, if the risk-return model outlined in equation (3) above is the true model of domestic risk and equation (2) is estimated instead, then the estimated value of Lambda according to equation (2) will overstate the returns to domestic risk as the returns to covariance risk are loaded onto the domestic variance risk parameter.

\section{(c) Data and Estimation Procedure}

The JSE/Actuaries All Share 40 Top Companies Index (ALSI40) and the Financial Times-Stock Exchange 100 Share Index (FTSE 100) acted as proxies for the domestic and international market portfolio, respectively. The daily closing levels were transformed into daily returns in the standard way as the natural logarithm of the ratio of the consecutive daily closing levels. The annual return on respective 90-day (3-month) Treasury bills, used as the proxies for the risk-free return in each country, were transformed into nominal daily rates for estimation purposes. The study period runs from 01/01/1996 to $31 / 12 / 2004$, for 2351 observations over the full 9 years. To aid interpretation the base used throughout for all the series was a percentage change, with a displayed unit of 1.00 equal to a $1 \%$ daily return. Table 1 , below, provides some of the important summary statistics for these series.

Table 1. Summary statistics for the various daily returns, JSE and LSE

\begin{tabular}{lccllcc}
\hline & SA return & UK return & SA risk free & UK risk free & SA equity premium & UK equity premium \\
Daily Mean & 0.042 & 0.018 & 0.033 & 0.014 & 0.009 & 0.003 \\
Daily Std Dev. & 1.201 & 1.161 & 0.008 & 0.003 & 1.202 & 1.161 \\
Maximum & 7.536 & 6.080 & 0.050 & 0.023 & 7.500 & 6.067 \\
Minimum & -11.863 & -5.175 & 0.020 & 0.003 & -11.899 & -5.728 \\
\hline
\end{tabular}

Note: The equity premia are defined as the "Returns" less the "Risk Free".

While the Table is largely self-explanatory, a few characteristics are noteworthy. Firstly, it is clear that equity returns are higher than the risk free returns over the sample period, which is as expected: being riskier, equities should pay a higher return than government paper. Note the extremely large difference of risk, as measures by the variance of the

${ }^{4}$ Bias amount between CAPM and ICAPM:

$$
\lambda_{C A P M}-\lambda_{\text {ICAPM }}=\kappa_{C o v}\left[\frac{\operatorname{cov}\left(r_{J}, r_{L}\right)}{\operatorname{var}\left(r_{j}\right)}\right]
$$

As the values for Kappa, domestic variance and the domestic/international return covariance are in practice all positive, equation (2) of the CAPM will overstate the value of Lambda if equation (3) of the ICAPM is the true specification. 
returns, between the risk-free and the equity returns. The JSE returns are also slightly more risky than the equities on the LSE, and consequently pay higher returns.

A final important point is that the domestic equity returns experienced a few extremely large price movements well in excess of the usual return movements. These will be considered outliers for the purpose of this study. Specifically, three price declines ${ }^{5}$ are of magnitudes so different from the rest of the sample that it is possible that they come from a completely different population. To aid convergence and provide a clearer picture to the underlying domestic risk-return relationship, the effects of these outliers are loaded onto an outlier dummy (see equation (6) above). There are no comparable outliers amongst the LSE returns.

The paper used the LSE FTSE100 index as a proxy for the international equity market in this paper as it satisfied two major conditions. First, to substitute for the international equity market the index used has to be a major international index that incorporates the equity information common to the world equity market. As a large world equity index with well-documented correlations with other major indices (Hamou et al. (1990)), the LSE clearly meets these criteria. Second, and most importantly, the world market proxy had to have a relatively concurrent trading with the JSE to ensure that the covariance and spillover terms used in the estimation contained the information from the same trading day as the JSE returns and volatilities. In this regard, the LSE is clearly the best choice, as its respective trading hours are far more concurrent with the JSE's than the other major comparable exchanges. This need for "clean" information periods was also the reason why a "World" index, such as the MSCI World Index, was not used.

In terms of estimation technique the ICAPM equations (6) through (10) were simultaneously estimated via Maximum Likelihood using the Marquardt algorithm, with the coefficient values from the initial OLS estimations employed as the starting values for the algorithm. For the simple CAPM, the model was estimated using the same procedure along with the imposition of the zero restrictions on the foreign variables as discussed above.

\section{RESULTS}

Table 2, below, presents the results of the simultaneous estimation of the ICAPM model and CAPM model.

\section{(a) Returns to Risks}

As can be seen in the table, the domestic coefficients for the price of domestic risk and covariance risk are all positive and highly significant, implying that the JSE impounds the information concerning both types of risk. The estimated daily price of domestic equity risk on the JSE is an increase in returns of $0.0279 \%$ (EAR: 7.28\%) for each single unit increase in volatility. Thus, for accepting the risk of an equity investment corresponding to level of uncertainty where the actual could be $1 \%$ above or below the expected return for the following trading day an investor gains an extra $0.03 \%$ return. The estimated daily price of covariance risk on the JSE is $0.0111 \%$ (EAR: 2.83\%) for every one unit of covariance risk between domestic returns and the returns on the LSE, with similar per risk unit interpretations as for the variance risk price. The domestic equity market therefore

\footnotetext{
5 These three outlier movements in the sample occur on the 17 May 2000 (-7.67\%), the 12 January $1998(-7.09 \%)$ and the 28 November $1997(-11.86 \%)$.
} 
Table 2. The price of risk on the JSE: ICAPM and CAPM estimations

\begin{tabular}{|c|c|c|c|c|c|c|}
\hline \multicolumn{5}{|l|}{$\overline{\text { ICAPM }}$} & \multicolumn{2}{|l|}{ CAPM } \\
\hline \multicolumn{5}{|c|}{$\begin{array}{l}\text { First Moments: } \\
r_{J, t}=\lambda_{J} h_{J, t}+\kappa_{j} \operatorname{cov} J L, t \\
r_{L, t}=\lambda_{J} h_{l, t}+\varepsilon_{L, t} \\
\text { Second Moments: } \\
h_{J, t}=\omega_{1}+\beta_{1, t} h_{J, t-1}+\rho_{1} h_{L, t}+\alpha_{1} \varepsilon_{j, t-1}^{2} \\
h_{L, t}=\omega_{2}+\beta_{2} h_{L, t-1}+\alpha_{2} \varepsilon_{L, t-1} \\
\operatorname{cov}_{L L, t}=\omega_{3}+\beta_{3} \operatorname{cov}_{J L, t-1}+\alpha_{3} \varepsilon_{J, t-1} \varepsilon_{L, t-1} \\
\end{array}$} & \multicolumn{2}{|c|}{$\begin{array}{l}\text { First Moment: } \\
r_{J, t}=\lambda_{J} h_{J, t}+\tau_{j o u t}+\varepsilon_{J, t} \\
\text { Second Moment: } \\
h_{J, t}=\omega_{1}+\beta_{1} h_{J, t-1}+\alpha_{1} \varepsilon_{j, t-1}^{2}\end{array}$} \\
\hline & ICAPM mo & & & CAPM model & & \\
\hline \multicolumn{7}{|c|}{ Panel A: Conditional First Moment(s) } \\
\hline & Coefficient & Std error & p-value & Coefficient & Std error & p-value \\
\hline $\begin{array}{l}\lambda_{1} \\
\lambda_{2} \\
\kappa_{1} \\
\end{array}$ & $\begin{array}{l}0.0279 \\
0.0565 \\
0.0111 \\
\end{array}$ & $\begin{array}{l}0.0001 \\
0.0320 \\
0.0003 \\
\end{array}$ & $\begin{array}{l}0.0000 \\
0.0780 \\
0.0000 \\
\end{array}$ & $\begin{array}{l}0.0455 \\
- \\
- \\
\end{array}$ & $\begin{array}{l}0.01807 \\
- \\
- \\
\end{array}$ & $\begin{array}{l}0.0117 \\
- \\
- \\
\end{array}$ \\
\hline \multicolumn{7}{|c|}{ Panel B: Conditional Second Moments } \\
\hline & Coefficient & Std error & p-value & Coefficient & Std error & p-value \\
\hline$\omega_{1}$ & 0.0008 & 0.0002 & 0.0000 & 0.0206 & 0.0038 & 0.0000 \\
\hline$\omega_{2}$ & 0.0032 & 0.0320 & 0.0790 & - & - & - \\
\hline$\omega_{3}$ & 0.0001 & 0.0003 & 0.0000 & - & - & - \\
\hline$\beta_{1}$ & 0.8202 & 0.0000 & 0.0000 & 0.9009 & 0.0071 & 0.0000 \\
\hline$\beta_{2}$ & 0.9131 & 0.0320 & 0.0780 & - & - & - \\
\hline$\beta_{3}$ & 0.8845 & 0.0003 & 0.0000 & - & - & - \\
\hline$\rho_{1}$ & 0.0287 & 0.0000 & 0.0000 & - & - & - \\
\hline$\alpha_{1}$ & 0.1146 & 0.0320 & 0.0780 & 0.0860 & 0.0071 & 0.0000 \\
\hline$\alpha_{2}$ & 0.0701 & 0.0003 & 0.0000 & - & - & - \\
\hline$\alpha_{3}$ & 0.0635 & 0.0000 & 0.0000 & - & - & - \\
\hline Log-Likelihood & -6584.34 & & & -3498.05 & & \\
\hline Pseudo $R^{2}$ & 0.0189 & & & 0.0049 & & \\
\hline
\end{tabular}

Note: - Denotes that the parameter was not estimated for that model.

Pseudo $\mathrm{R}^{2}$ 's are computed as the ratio of the sum of squared fitted values and the sum of the squared excess returns.

appears to price in both types of risks. Given the relative magnitudes of the two risks, the domestic equity market views the uncertainty regarding the return on domestic equities higher than the uncertainty regarding the potential diversification benefits. The representative investor on the JSE appears to be more concerned with domestic returns than international diversification, which is as expected given that domestic investors hold most ${ }^{6}$ of the JSE ALSI40.

The estimated price of domestic risk according to the simple CAPM model is $0.0455 \%$ (EAR: $12.29 \%$ ). That this value is higher and slightly less significant than the value estimated according to the ICAPM supports the assertion of Scruggs (1998) that the simple CAPM is a misspecification of the domestic returns to risk, and that the ICAPM with the included covariance risk is a better specification. This is a potentially important finding for much of the domestic studies using the standard CAPM as the pricing specification, as their results could be potential biased through under specification. The calculated Pseudo $\mathrm{R}^{2}$ 's further support this notion that the ICAPM model is a better specification of domestic equity risk-return behaviour.

For the LSE, the respective price of domestic risk is estimated at 0.0565\%(EAR: $15.49 \%$ ). While this coefficient is positive, it is only significant at the $10 \%$ level, echoing the mixed literature of such an estimated risk-return relationship under one-factor

${ }^{6}$ No actual data is collected by the JSE on the foreign ownership of the ALSI40, though it is plausible to assume that it is not greater than the domestic ownership. 
CAPM models. It is also larger than that for the JSE, though it is likely that this CAPM model is underspecified and the Lambda value biased, so this relatively higher risk price should not be considered a robust result.

\section{(b) Variance and Covariance Specifications}

As is expected the coefficients for the $\operatorname{GARCH}(1,1)$ specification of the variance terms for both markets and in both models are all significant, and are of the usual sign and magnitudes. ${ }^{7}$ Crucially, the variance coefficients satisfy the twin conditions of non-negativity and covariance stationarity. ${ }^{8}$ For the covariance specification, the significant positive coefficient of the last term is as it should be: large movements by the two respective indices in the same direction leads to increased covariance. Movements in opposite directions imply decreased covariance.

The spillover coefficient in the ICAPM model, $\rho$, is both significant and positive. In line with the literature, this paper finds that increased volatility on the international market is associated with increased volatility on the domestic market. Investors on the JSE appear to price in information from the foreign equity market into the domestic equity market. An increase in volatility on the international equity market, proxied by the LSE, is associated with an increase in domestic volatility of $0.0287 \%$. Note that, due to the use of concurrent daily returns, this is not evidence of causality running from the international market to the JSE, but only evidence that movements in international volatility are associated with movements in local volatility.

\section{(c) Market Segmentation and the Gains from Diversification}

While admittedly a broad brush, the significant effect that domestic risk has in the ICAPM model leads to the suggestion that the domestic market is to some degree segmented from the international market, as domestic information contains significant market information regarding domestic equities that is not contained in the international market risk information. Indeed, the large difference in relative risk prices among domestic equities implies that this segmentation is quite substantial.

Through international diversification, investors can gain the same return for lower volatility, or, correspondingly, higher returns for the same volatility. From equation (5), it is also possible to get a measure of this gain from having an internationally diversified equity portfolio following De Santis and Gerard. While the measure exhibits significant time variation given the interaction of the time-varying variances and covariances, for the same level of volatility as the domestic market portfolio the expected average daily gain from an internationally diversified portfolio over the full sample is $0.0238 \%$ per day. As the mean return over the risk free rate in South Africa over this period of $0.0074 \%$, this is a substantial expected benefit. It is interesting to note that the $6.285 \%$ effective annual rate of this benefit is far higher that found by De Santis et al. for the US market $(2.11 \%)$, implying that domestic investors have more to gain from international diversification than investors with large home markets. This result of significantly larger returns to international diversification for investors with small home markets is also found by Nilsson (2002), who finds effective annual diversification returns for the smaller markets

7 Daily Half Lives by equation: Eq.(6): 10.2 days; Eq.(7): 40.9 days; Eq.(8): 12.9 days, Eq.(10): 52.5 days. Half Lives, $\mathrm{i}$, were found by solving $\left(\alpha_{i}+\beta_{i}\right)^{\mathrm{i}}=0.5$.

${ }^{8}$ Covariance stationarity exists only if: $\alpha_{i}+\beta_{i}<1$. 
of France, UK and Switzerland ranging from $4.46 \%$ to $9.60 \%$, and far smaller effective annual returns of $0.73 \%$ to $0.98 \%$ for the US and Japanese markets.

\section{CONCLUSIONS}

This paper estimated a two-factor ICAPM model using a parsimonious bivariate GARCH(1,1)-M model that incorporated international volatility spillovers to estimate the price of domestic (variance) and international diversification (covariance) risk on the JSE. Using the LSE as the proxy for the international equity market, this paper found a number of results regarding risk and return on the JSE.

First, and most importantly, this paper found significant evidence that the domestic equity market rewards risk taking; that the fundamental relationship between risk and reward exists among South African equities. The representative domestic investor on the JSE receives higher returns for investing in equities when they have higher risks associated with them.

Specifically, the paper found that the daily return to domestic equity risk was $0.0279 \%$ for every one unit increase in risk. The JSE rewards investors who hold equities when there is greater uncertainty around the expected return of such equities. As the average mean daily equity premium (the equity return over the risk free return) over the sample is $0.007 \%$, this return to risk is quite a substantial relative return on risk.

The paper also found evidence that the domestic market rewards the risk due to decreases in the diversification property. This paper found that the reward to the representative investors for diversification risk is an expected increase in daily returns of $0.0111 \%$ for every one-unit decrease in diversification benefits.

With regards to the relative domestic significance of the risks, for the representative local investor the risk associated with the variance of domestic returns is far more important that the risk associated with international diversification risk, with variance risk being priced in at almost three times the amount that covariance risk is priced in. This is a largely expected result given that the representative investor on the JSE is likely to be more concerned with the gains from domestic returns than with the benefits of international diversification.

The spillover coefficient is found to be both significant and positive. Increases in the foreign volatility level tend to be associated with increases in the domestic volatility level. The domestic equity appears to significantly price in information from the international equity market. This result is in agreement with the literature, and justifies its inclusion in the model.

The paper also finds evidence that the JSE is imperfectly integrated with the world equity market. Information concerning the domestic equity market provides additional significant information concerning domestic returns above and beyond that provided by the international market risk.

Having an internationally diversified portfolio allows domestic equity investors to lower risks for the same return, or conversely, higher returns for the same risk. This study found that this international diversification premium is quite substantial, with domestic investors able to earn an expected $6.285 \%$ additional effective annual return for an international portfolio with the same variance (risk) as a domestic portfolio.

The simple CAPM asset-pricing model, whereby the variance of the market portfolio is the sole determinant of the equity return premium, ignores important risk on the JSE. 
This will bias the return to domestic risk upwards as information concerning covariance risk is loaded onto to that parameter in the absence of a separate specification.

Lastly, the estimated coefficients of the second moments show that, in line with the literature, the variances of the LSE and JSE's equities are both time-varying. In addition, there is significant evidence that the covariance between the two indices is time-varying as well. Periods of high (low) variance/covariance follow periods of high (low) variance/ covariance. From an investors' perspective, this suggests that it is possible to (partly) gauge tomorrows' variance or covariance between the markets based on today's variance or covariance between the markets.

In conclusion then, this paper found that the domestic equity market in South Africa compensates for both the risk inherent in the uncertainty of future domestic returns and the risk that the diversification benefit of investing internationally might decrease as domestic and international returns move more closely together. In short, investors on the JSE ALSI40 index received higher returns as a reward for taking on higher risk.

\section{REFERENCES}

ABEL, A. (1988). Stock prices under time-varying dividend risk: An exact solution in an infinite horizon general equilibrium model. Journal of Monetary Economics, 22: 375-393.

BOLLERSLEV, T., CHOU, T. Y. and KRONER, K. F. (1992). Arch modelling in finance: A review of the literature. Review of Econometrics, 52: 5-59.

CAMPBELL, J. Y. (1987). Stock returns and the term structure. Journal of Financial Economics, 18:373-399.

CHAN, K., KAROLYI, G. and STULZ, R. (1992). Global financial markets and the risk premium on U.S. equity. Journal of Financial Economics, 32: 137-167.

CHOU, R., ENGLE, R. and KANE, A. (1992). Measuring risk aversion from excess returns on a stock index. Journal of Econometrics, 52: 201-224.

DE SANTIS, G. and GERARD, B. (1997). International asset pricing and portfolio diversification with time-varying risk. The Journal of Finance, 77(5): 1881-1912

DEAN, W. and FAFF, R. (2001). The intertemporal relationship between market returns and variance: An Australian perspective. Accounting and Finance, 41: 169-196.

ENGLE, R. (2004). Risk and volatility. Financial models and financial practice. Journal of Finance, 94(2): 405-420.

ENGLE, R., LILLIAN, D. and ROBBINS, R. (1987). Estimating time varying risk premia in the term structure: The Arch-M Model. Econometrica, 55: 391-407.

FRENCH, K., SCHWERT, W. and STAMBAUGH, R. (1987). Expected returns and volatility. Journal of Financial Economics, 19: 3-29.

GLOSTEN, L. R. and JAGANNATHAN, R. (1987). Money, real activity and security prices. Unpubished Manuscript, University of California at San Diego.

GLOSTEN, L. R., JAGANNATHAN, R. and RUNKLE, D. (1993) On the relation between the expected value and the volatility of the nominal excess return on stocks. Journal of Finance, 48: 1779-1801.

HAMOU, Y., MASULIS, R. and NG, V. (1990). Correlations in price changes and volatility across international markets. Review of Financial Studies, 3 (2): 281-307.

HANSSON, B. and HÖRDAHL, P. (1997) Changing risk premia: Evidence from a small open economy. Scandinavian Journal of Economics, 99(2): 335-350.

JOCHUM, C. (1999). Volatility spillovers and the price of risk: Evidence from the Swiss stock market. Empirical Economics, 24: 303-22.

LIN, W., ENGLE, R. and ITO, T. (1994). Do bulls and bears cross borders? International Transmission of Stock Returns and Volatility. The Review of Financial Studies, 7(3): 507-538.

LITNER, J. (1965). The valuation of risk assets and the selection of risky investments in stock portfolios and capital budgets. Review of Economics and Statistics, 47: 13-47.

MARKOWITZ, H. (1952). Portfolio selection. Journal of Finance, 7(1): 77-91.

MERTON, R. (1973). An intertemporal capital asset pricing model. Econometrica, 867-887.

NILSSON, B. (2002). International asset pricing and the benefits form world market diversification. Lund University, Department of Economics Working Paper 2002:1.

PAGAN, A. R. and HONG, Y. S. (1991). Nonparametric estimation and the risk premium. In William Barnett, James Powell, and George Tauchen (eds): Nonparametric and Semiparametric Methods in Econometrics and Statistics. Cambridge: Cambridge University Press, 51-75.

SAMOUILHAN, N. L. (2006). The relationship between the international equity market and the JSE. South African Journal of Economics, 74(2): 248-260. 
SCRUGGS, J. T. (1998). Resolving the puzzling intertemporal relation between the market risk premium and the conditional market variance: A two-factor approach. Journal of Finance, 53: 575-603.

SHARPE, W. (1964). Capital market prices: A theory of market equilibrium under conditions of risk. Journal of Finance, 19: 425-442.

TOBIN, J. (1958). Liquidity preference as behaviour towards risk. Review of Economic Studies, 25(2): 65-86. 